\title{
First Caesarean Section and Subsequent Infertility
}

\author{
Mojgan Barati, ${ }^{1,2}$ Fatemeh Lotfi Jalalabadi, ${ }^{3,{ }^{*}}$ and Farideh Moramezi ${ }^{1,2}$ \\ ${ }^{1}$ Fertility, Infertility and Perinatology Research Center, Imam Khomeini Hospital, Ahvaz Jundishapur University of Medical Sciences, Ahvaz, IR Iran \\ ${ }^{2}$ Associate Professor, Department of Obstetrics and Gynecology, Faculty of Medicine, Ahvaz Jundishapur University of Medical Sciences, Ahvaz, IR Iran \\ ${ }^{3}$ Resident, Department of Obstetrics and Gynecology, Student Research Committee, Ahvaz Jundishapur University of Medical Sciences, Ahvaz, IR Iran \\ "Corresponding author: Fatemeh Lotfi Jalalabadi, Associate Professor, Department of Obstetrics and Gynecology, Faculty of medicine, Ahvaz Jundishapur University of Medical \\ Sciences, Ahvaz, IR Iran. E-mail: ali_moarref@yahoo.com
}

Received 2017 March 11; Revised 2017 June 07; Accepted 2017 July 04.

\begin{abstract}
Background: Caesarean section (CS) is one of the most commonly undertaken operations worldwide with numerous potential complications such as subsequent infertility. Thus, the aim of this study was to evaluate subsequent infertility after CS.

Methods: This retrospective epidemiological study was conducted in Obstetrics and Gynecology of Ahvaz Imam Hospital from 2011 to 2015. During the five years, 2047 patient records were collected representing that only 218 patients had secondary infertility after CS or vaginal delivery (including 114 (52.29\%) after CS and 104 (47.7\%) after vaginal delivery). Then, information of all patients was extracted from infertility clinic records.

Results: The results showed that there was no significant difference between the groups in terms of demographic features and sign and symptoms such as dysmenorrhea $(\mathrm{P}=0.386)$, dyspareunia $(\mathrm{P}=0.357)$, hirsutism $(\mathrm{P}=0.622)$, and galactorrhea $(\mathrm{P}=0.352)$. Moreover, associated disorders including Men disorders $(\mathrm{P}=0.577)$, Uterine disorders $(\mathrm{P}=0.286)$, Fallopian tube disorders $(\mathrm{P}=0.394)$, and Ovulation disorders $(\mathrm{P}=0.21)$ did not have any significant differences between the groups.

Conclusions: The results of this study suggest that CS did not increase the risk of subsequent infertility when compared to vaginal delivery. Therefore, in patients who have infertility problems after the first CS, we should evaluate other reasons in order to treat it.
\end{abstract}

Keywords: Caesarean Section, Vaginal Delivery, Subsequent Infertility

\section{Background}

Caesarean section (CS) is one of the most commonly undertaken operations worldwide and the frequency and desire of pregnant women to have CS rather than vaginal delivery is growing, which is not done in a standardized way (1). On the other hand, CS is a surgical procedure with numerous potential complications for both mother and child such as infection, organ injuries (2), thromboembolic complications (3), uterine rupture, and placental anomalies such as placenta previa, increta, or accrete (4). Recently it has been demonstrated that subsequent infertility is probably one of the serious complications of CS, which has not been well studied (4-7). On the other hand, it has been accepted that chronic diseases have some stresses for the body; especially, when they cause weight loss, they can interfere with ovulation, which is the main cause of infertility (8). A recent meta-analysis study evaluated the impact of CS on subsequent infertility reporting that CS decreased the subsequent birth rate by $11 \%$ (8). Moreover, some studies have reported that elective CS does not appear to cause infertility. In a study performed by Oral $\mathrm{E}$ et al., it was demonstrated that in recent studies, which have tried to explain the association between CS and subsequent fertility, some biases and confounding factors might lead to some unacceptable adverse effects of emergency CS (9). Furthermore, Smith GC et al. showed that it is unlikely that performing CS for the first pregnancy decreases the fertility of women in the second pregnancy (10). As to the best of our knowledge, there is not enough prospective study about this issue and on the other hand, due to antithesis results reported by the limited studies, this study was designed to evaluate subsequent infertility after CS.

\section{Methods}

\subsection{Study Design and Target Group}

This retrospective epidemiological study was conducted in obstetrics and gynecology of Ahvaz Imam hospital, south-west of Iran, from November 2011 to May 2015. All the patients with infertility after the first delivery were enrolled in the study. Inclusion criteria included patients referring to the infertility clinic of Ahvaz hospitals with a diagnosis of infertility (inability to conceive after having regular unprotected sex for more than 12 months, or female who cannot carry a full term pregnancy). Exclusion criteria consisted of patients with history of infertility before the first delivery, history of surgery on the pelvis, uterus, ovaries, and fallopian tubes after the first delivery, history 
of recurrent miscarriage, flawed and insufficient information in patients' records and lack of access to the patient.

\subsection{Participants}

The study flowchart is shown in Figure 1. During the five years, 2047 patient's records were collected indicating that 1504 cases had primary infertility, 56 cases had recurrent miscarriage, 127 cases had only one abortion, 142 cases had more than one CS and only 218 patients had secondary infertility after CS or vaginal delivery (including 114 (52.29\%) after CS and 104 (47.7\%) after vaginal delivery). Among 114 pregnant women undergoing CS, 63 cases (55.26 $\%$ ) had emergency CS and 51 cases (44.73\%) had elective CS. 218 patients who had been diagnosed with secondary infertility by an infertility specialist were included based on inclusion and exclusion criteria. Then, information of all patients was extracted from infertility clinic records including demographic features, type and duration of contraceptive methods, past medical history, and infertility problems. In case of incomplete information, we assessed the patients in a five-minute phone call for completing missing data and if we needed to see the patient's records, we arranged face-to-face appointments. If we needed to contact the patients to complete information, we interviewed just the patient; first, we explained persuasively the issue, methods, and purpose of our study to the patient and the patient's verbal consent was obtained regarding her participation and completing information. If the patient did not desire to participate in the study, we excluded her from the study. The study received an ethics approval from the ethics committee of Ahvaz Jundishapur University of Medical Sciences, and informed consent was obtained only from patients who participated in phone call assessment or in face-to-face appointments.

\subsection{Data Analysis}

Data were analyzed and reported only for patients with complete information. Statistical analysis of data was performed using SPSS version 22 software. Chi-square test was used to compare qualitative variables between groups. Kolmogorov-Smirnov test was used to evaluate the normal distribution of quantitative parameters. Student t-test and paired t-test were used for variables with normal distribution while Mann-Whitney and Wilcoxon tests were used for variables without normal distribution. The two tailed $\mathrm{P}$ value less than 0.05 was considered significant.

\section{Results}

Regarding the demographic features, age of participants was similar $(\mathrm{P}=0.086)$ between the two groups (Table 1). The other features such as past medical history ( $\mathrm{P}>$
0.05), type ( $\mathrm{P}=0.711)$ and duration of using contraceptive methods $(P=0.194)$, and the interval between decision to pregnancy and referring to infertility clinics were similar between the patients with different methods of first delivery $(\mathrm{P}=0.268)$.

Furthermore, we found that there were no significant differences between the groups in terms of sign and symptoms such as dysmenorrhea $(\mathrm{P}=0.386)$, dyspareunia $(\mathrm{P}=$ $0.357)$, hirsutism $(P=0.622)$, and galactorrhea $(P=0.352)$. Moreover, associated disorders including Men disorders ( $\mathrm{P}$ $=0.577)$, Uterine disorders $(P=0.286)$, Fallopian tube disorders $(\mathrm{P}=0.394)$, and Ovulation disorders $(\mathrm{P}=0.21)$ did not have significant differences between the groups.

\section{Discussion}

The aim of this study was to find a correlation between first CS and subsequent infertility. According to our results, CS did not increase the risk of subsequent infertility when compared to vaginal delivery. The study performed by Saraswat L et al. showed that women with secondary tubal infertility had the same rate of CS in the first delivery as compared to the other infertile women (21.4\% vs. $21.6 \%$ ) but they showed that CS was significantly lower in fertile control group (14.5\%). After adjusting for confounding factors, they found that CS did not have any significant association with tubal infertility. However, they found that other factors such as history of intrauterine device use, pelvic inflammatory disease, ectopic pregnancy, endometriosis, and previous pelvic surgery might lead to secondary tubal infertility (11). Moreover, another study performed by Oral E et al. showed that elective CS did not have any significant correlation with subsequent infertility (9). Smith GC et al. showed that women with planned CS due to breech presentation had higher risk of infertility for the second birth as compared to women with vaginal delivery. However, after adjusting for confounding factors such as maternal and obstetric characteristics, this correlation did not remain significant. Moreover, they found that there is no association between the type of delivery and the number of pregnancy losses between the first and second births (10). All these studies found results similar to our findings.

On the other hand, Tollsnes MC et al. evaluated 596,341 women who had their first delivery during 1967-1996 and showed that CS increased the infertility in the second birth (if the infant survived than if it was stillborn or died). This suggests that the increasing infertility was not related to the indication of CS; therefore, reduced fertility in the second birth was due to the CS complications (12). On the other hand, Collin SM et al. evaluating 35,398 women of childbearing age (15 - 49 years) demonstrated that CS is associated with reduction in subsequent natural fertility 


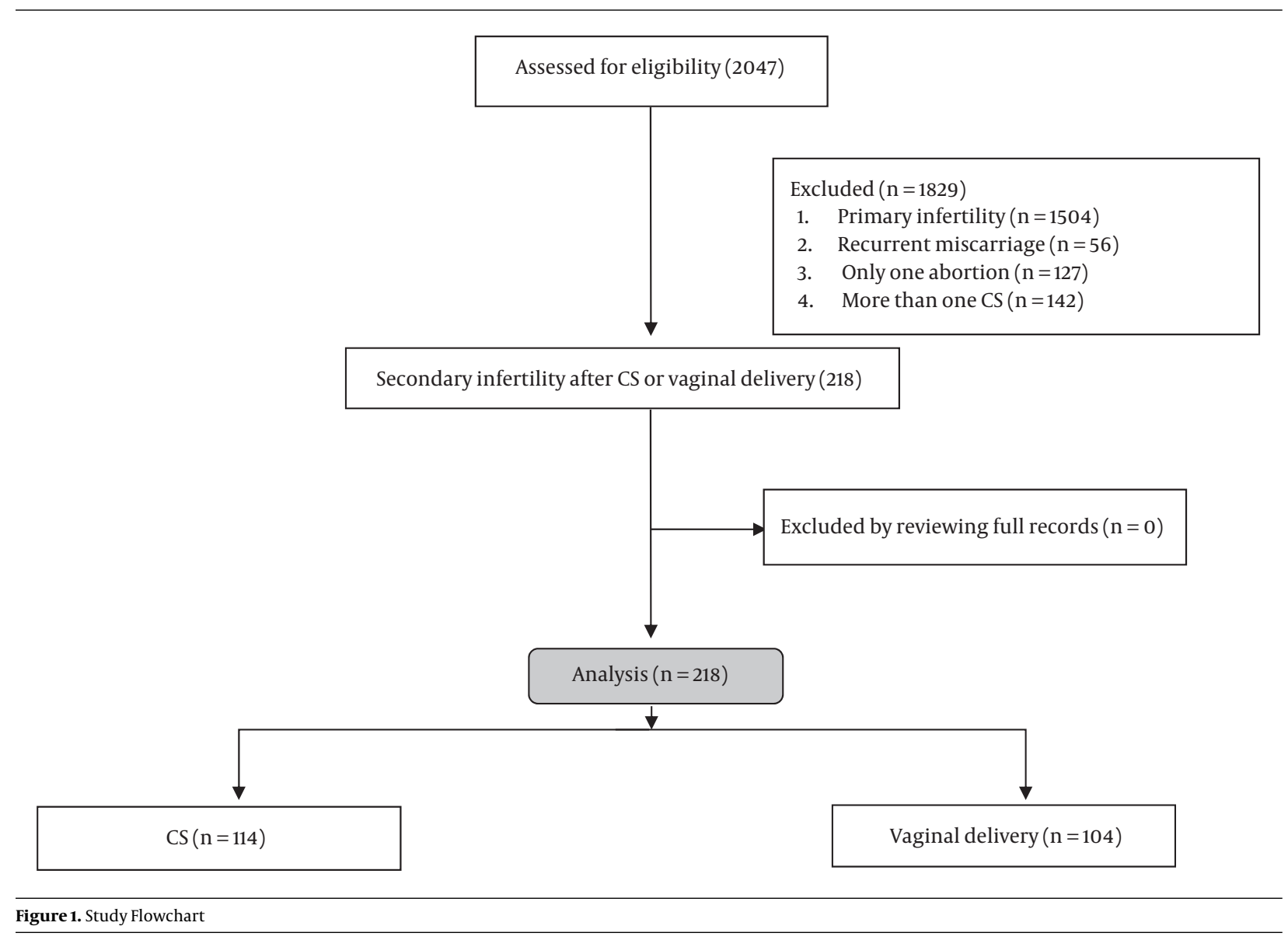

in sub-Saharan Africa. On the other hand, infertility after CS was reported in developed countries, which reflects the differences in pathological and psychological factors, because most of CS indications in sub-Saharan Africa are emergency procedures for maternal indication, while in developed countries the desire of women for CS is the most indication for CS (13). Furthermore, Tanimura S et al. assessing 22 women with secondary infertility showed that infertility was associated with post-cesarean scar defect (14). Kjerulff $\mathrm{KH}$ et al. evaluated 52,498 women who had a first singleton live birth and showed that women who deliver their first child by CS have less chance to have a subsequent birth. They found a 15\% reduction in subsequent birth rate after CS (15). Another study performed by Jacob L et al. on 6483 patients in CS group and 6483 in VD group demonstrated that CS is associated with an increased risk of sterility and subsequent infertility in Germany. In this study, they found that CS decreased subsequent pregnancies as polycystic ovary syndrome and deterioration of menstrual cycle did it (16). Gurol-Urganci I et al. assessing 1,047,644 first births to low-risk women using routinely collected data found that there is no or only a slight effect for CS on future fertility; they demonstrated that it is due to residual bias in their adjusted results that would lead to an overestimate of the effect of CS on fertility (17). A recent metaanalysis study in 2013 evaluated the impact of CS on subsequent infertility and reported that CS decreased the subsequent birth rate by $11 \%$ (8); therefore, in this meta-analysis (on 18 cohort studies), which is the newest paper regarding the impact of CS on infertility, this effect was proved and the challenges about this subject are related to older papers, which had some limitations such as small sample size, confounding variables, and lack of studying any variable affecting subsequent infertility, which are factors that were considered in our study. The results of these studies are in contrast to ours, which may be due to the different sample size, different methods, and different population features.

\subsection{Limitations}

We included all patients with subsequent infertility during five years. 2047 patient's records were collected, 
Table 1. Study Variables in CS and Vaginal Delivery Groups ${ }^{\mathrm{a}}$

\begin{tabular}{|c|c|c|c|}
\hline \multirow[t]{2}{*}{ Variable } & \multicolumn{2}{|r|}{ Group } & \multirow[t]{2}{*}{ P Value } \\
\hline & $\operatorname{CS}(\mathrm{N}=114)$ & Vaginal Delivery $(N=104)$ & \\
\hline Age, $y$ & $31.85 \pm 4.82$ & $30.66 \pm 5.41$ & 0.086 \\
\hline Duration of using contraceptive methods, $y$ & $3.11 \pm 1.41$ & $2.88 \pm 1.17$ & 0.194 \\
\hline Interval between decision to pregnancy and referring to infertility clinics, mo & $23.35 \pm 12.92$ & $25.56 \pm 16.45$ & 0.268 \\
\hline Contraceptive methods & & & 0.711 \\
\hline Withdrawal & $69(60.5)$ & $69(66.3)$ & \\
\hline LD & $27(23.7)$ & $18(17.3)$ & \\
\hline Condom & $15(13.2)$ & $14(13.5)$ & \\
\hline Etc. & $3(2.6)$ & $3(2.9)$ & \\
\hline \multicolumn{4}{|l|}{ Past medical history } \\
\hline Thyroid & $7(6.1)$ & $10(9.6)$ & 0.339 \\
\hline Diabetes & $16(14)$ & $7(6.7)$ & 0.08 \\
\hline \multicolumn{4}{|l|}{ Sign and symptoms } \\
\hline Dysmenorrhea & $27(23.7)$ & $30(28.8)$ & 0.386 \\
\hline Dyspareunia & $23(20.2)$ & $16(15.4)$ & 0.357 \\
\hline Hirsutism & $33(28.9)$ & $27(26)$ & 0.622 \\
\hline Galactorrhea & $8(7)$ & $11(10.6)$ & 0.352 \\
\hline \multicolumn{4}{|l|}{ Associated disorders } \\
\hline Men disorders & $86(75.4)$ & $75(72.1)$ & 0.577 \\
\hline Uterine disorders & $11(9.6)$ & $6(5.8)$ & 0.286 \\
\hline Fallopian tube disorders & $23(20.2)$ & $26(25)$ & 0.394 \\
\hline Ovulation disorders & $42(36.8)$ & $30(28.8)$ & 0.21 \\
\hline
\end{tabular}

${ }^{\mathrm{a}}$ Values are expressed as No. (\%).

but the majority of them were excluded. Therefore, we should perform a study during 10 or 15 years in order to have larger sample sizes for epidemiological studies to be able to draw a definite conclusion about the relationship of cesarean with infertility.

\subsection{Conclusions}

The results of this study suggest that CS did not increase the risk of subsequent infertility when compared to vaginal delivery. Therefore, in patients who have infertility problems after the first CS, we should evaluate other reasons in order to treat it.

\section{Acknowledgments}

This study was financially supported by technology and research development department of Jundishapur University of Medical Sciences, Ahvaz, Southwest of Iran.
We gratefully acknowledge the dedicated efforts of the coordinators and the clinical research development units (CRDU) of Ahvaz Imam hospital.

\section{Footnote}

Conflicts of Interest: The authors have no conflicts of interests regarding the content of this article.

\section{References}

1. Coronis collaborative group, Abalos E, Addo V, Brocklehurst P, El Sheikh M, Farrell B, et al. Caesarean section surgical techniques: 3 year follow-up of the CORONIS fractional, factorial, unmasked, randomised controlled trial. Lancet. 2016;388(10039):62-72. doi: 10.1016/S0140-6736(16)00204-X. [PubMed: 27155903].

2. Dahlgren LS, von Dadelszen P, Christilaw J, Janssen PA, Lisonkova S, Marquette GP, et al. Caesarean section on maternal request: risks and benefits in healthy nulliparous women and their infants. $J \mathrm{Ob}$ stet Gynaecol Can. 2009;31(9):808-17. doi: 10.1016/S1701-2163(16)342992. [PubMed: 19941705]. 
3. Clark SL, Christmas JT, Frye DR, Meyers JA, Perlin JB. Maternal mortality in the United States: predictability and the impact of protocols on fatal postcesarean pulmonary embolism and hypertensionrelated intracranial hemorrhage. Am J Obstet Gynecol. 2014;211(1):32 e1-9. doi: 10.1016/j.ajog.2014.03.031. [PubMed: 24631705].

4. Gilliam M. Cesarean delivery on request: reproductive consequences. Semin Perinatol. 2006;30(5):257-60. doi: 10.1053/j.semperi.2006.07.005. [PubMed:17011396].

5. Hall MH, Campbell DM, Fraser C, Lemon J. Mode of delivery and future fertility. Br J Obstet Gynaecol. 1989;96(11):1297-303. doi: 10.1111/j.14710528.1989.tb03227.x. [PubMed: 2611168].

6. Hemminki E, Graubard BI, Hoffman HJ, Mosher WD, Fetterly K. Cesarean section and subsequent fertility: results from the $1982 \mathrm{Na}-$ tional Survey of Family Growth. Fertil Steril. 1985;43(4):520-8. doi: 10.1016/S0015-0282(16)48491-8. [PubMed: 3872816].

7. Mollison J, Porter M, Campbell D, Bhattacharya S. Primary mode of delivery and subsequent pregnancy. BJOG. 2005;112(8):1061-5. doi: 10.1111/j.1471-0528.2005.00651.x. [PubMed: 16045518].

8. Gurol-Urganci I, Bou-Antoun S, Lim CP, Cromwell DA, Mahmood TA, Templeton A, et al. Impact of Caesarean section on subsequent fertility: a systematic review and meta-analysis. Hum Reprod. 2013;28(7):1943-52. doi: 10.1093/humrep/det130. [PubMed: 23644593].

9. Oral E, Elter K. The impact of cesarean birth on subsequent fertility. Curr Opin Obstet Gynecol. 2007;19(3):238-43. doi: 10.1097/GCO.ob013e32810fd797. [PubMed: 17495639].

10. Smith GC, Wood AM, Pell JP, Dobbie R. First cesarean birth and subsequent fertility. Fertil Steril. 2006;85(1):90-5. doi: 10.1016/j.fertnstert.2005.07.1289. [PubMed: 16412736].

11. Saraswat L, Porter M, Bhattacharya S, Bhattacharya S. Caesarean sec- tion and tubal infertility: is there an association? Reprod Biomed Online. 2008;17(2):259-64. doi: 10.1016/S1472-6483(10)60203-9. [PubMed: 18682001].

12. Tollanes MC, Melve KK, Irgens LM, Skjaerven R. Reduced fertility after cesarean delivery: a maternal choice. Obstet Gynecol. 2007;110(6):1256-63. doi: 10.1097/01.AOG.0000292089.18717.9f. [PubMed: 18055718].

13. Collin SM, Marshall T, Filippi V. Caesarean section and subsequent fertility in sub-Saharan Africa. BJOG. 2006;113(3):276-83. doi: 10.1111/j.14710528.2006.00846.x. [PubMed: 16487198].

14. Tanimura S, Funamoto H, Hosono T, Shitano Y, Nakashima M, Ametani Y, et al. New diagnostic criteria and operative strategy for cesarean scar syndrome: Endoscopic repair for secondary infertility caused by cesarean scar defect. J Obstet Gynaecol Res. 2015;41(9):1363-9. doi: 10.1111/jog.12738. [PubMed: 26111547].

15. Kjerulff KH, Zhu J, Weisman CS, Ananth CV. First birth Caesarean section and subsequent fertility: a population-based study in the USA, 2000-2008. Hum Reprod. 2013;28(12):3349-57. doi: 10.1093/humrep/det343. [PubMed: 24021550].

16. Jacob L, Weber K, Sechet I, Macharey G, Kostev K, Ziller V. Caesarean section and its impact on fertility and time to a subsequent pregnancy in Germany: a database analysis in gynecological practices. Arch Gynecol Obstet. 2016;294(5):1005-10. doi: 10.1007/s00404-0164160-4. [PubMed: 27488697].

17. Gurol-Urganci I, Cromwell DA, Mahmood TA, van der Meulen JH, Templeton A. A population-based cohort study of the effect of Caesarean section on subsequent fertility. Hum Reprod. 2014;29(6):1320-6. doi: 10.1093/humrep/deu057. [PubMed: 24781430] 